\title{
Editorial: Sustainable Processing Innovations for Foods
}

\author{
Cristobal N. Aguilar ${ }^{1 *}$, Lourdes Maria Correa Cabral ${ }^{2}$ and Paula Jauregi ${ }^{3}$ \\ ${ }^{1}$ Food Research Department, School of Chemistry, Universidad Autónoma de Coahuila, Saltillo, Mexico, ${ }^{2}$ Brazilian \\ Agricultural Research Corporation, Brasilia, Brazil, ${ }^{3}$ Department of Food and Nutritional Sciences, University of Reading, \\ Reading, United Kingdom
}

Keywords: sustainable food processing, fruit waste, lactic acid bacteria, probiotic, food by-product

\section{Editorial on the Research Topic}

\section{Sustainable Processing Innovations for Foods}

This Research Topic highlights current knowledge on the most recent innovations, emerging technologies and strategies based on sustainable food design. In this specific issue, two important Research Topics have been addressed to outline the priorities for sustainable food processing innovations: (a) the use of probiotics as bio-preservative of fruit pomace beverages and bio-control processes in fruit and fresh products; and (b) the use of food residues and by-products as food ingredients.

Sustainable food processing innovations require a reduction in energy, water and waste through processing, as well as an indirect impact on food losses, under-optimal utilization and unnecessary quality decay within the supply chain. In addition to their contribution to the improvement of the world food processing industries, new and improved food products, resource-efficient manufacturing processes, integrated, and transparent supply chains and enhanced innovation capacity are needed, which are encouraged.

Sustainable food processing innovations are needed to combat the dramatic increase in the population of nearly 10 billion people worldwide, which is why serious and important challenges need to be faced in a guaranteed way to ensure universal access to food, health care, water, sanitation, energy, education, and housing. In the case of food, innovations in food processing techniques can make a significant contribution to meeting the needs of the future world population with regard to the quality, quantity, and sustainability of their food intake.

The first paper (Dias et al.) is a collaborative effort between researchers from Brazilian institutions, the Federal University of Rio de Janeiro and the Brazilian Agricultural Research Corporation. The paper describes the use of acid lactic bacteria as a bio-preservant for grape pomace beverage, improving the stability of the final product and demonstrating that probiotic juice is an alternative to probiotic beverages derived from dairy products. This work was carried out in the light of the fact that the production of agricultural residues is a global economic and environmental problem, and its use in addition to probiotic juice can be an appropriate solution for the food industry. Studies using fruit residues as an ingredient are not novel; however, a definitive solution to this environmental problem has not yet been identified. Besides being a starter culture, it can function as a bio-preservative and improve the stability of the final product. Probiotic beverage obtained is a promising application for grape pomace. Further studies are needed to investigate the causes and interactions of grape pomace compounds and lactic acid bacteria against foodborne pathogens.

The second paper (Torres-León et al.) is a contribution from the Mexican Bioprocess and Bioproduct Research Group of the Food Research Department of the Universidad Autónoma de Coahuila. Coauthors carried out a critical analysis of the opportunities for using food waste and bioproducts to minimize malnutrition and hunger in developing countries. The objective 
of this contribution is to project the potential of food waste and by-products as a sustainable processing innovation for new food, in particular on the basis that food production and processing in developing countries generates high levels of waste and by-products, resulting in negative environmental impacts and significant costs. However, these biomaterials have ample potential for producing food additives which, in turn, will minimize malnutrition and hunger in the developing countries where they are produced. Many of these biomaterials are a source of valuable compounds such as proteins, lipids, starch, micronutrients, bioactive compounds, and dietary fibers. In addition, anti-nutritional factors present in some by-products may be minimized through biotechnological processes for use as a food additive or in the formulation of balanced foods.

Third paper (Linares-Morales et al.) describes the use of lactic acid bacteria as a sustainable option for biocontrol processes in fruit and fresh products. This is the contribution made by Mexican researchers at the Universidad Autónoma de Chihuahua. This review describes the main methods of conservation as well as the emerging methods used to preserve fresh fruit and vegetables. The use of lactic acid bacteria is described as a guaranteed and effective technique for enhancing bio-preservation as a proposal for future research. Extending the shelf life of fruit and vegetables during post-harvest is emerging as an attractive alternative method for ensuring the microbial safety of fresh fruit and vegetables. This method has been an important research subject to replace traditional and common conservation methods based on transpiration, respiration and microbial spoilage.

\section{AUTHOR CONTRIBUTIONS}

All authors listed have made a substantial, direct and intellectual contribution to the work, and approved it for publication.

\section{ACKNOWLEDGMENTS}

The authors thank Frontiers for all their support.

Conflict of Interest: The authors declare that the research was conducted in the absence of any commercial or financial relationships that could be construed as a potential conflict of interest.

Copyright (c) 2020 Aguilar, Cabral and Jauregi. This is an open-access article distributed under the terms of the Creative Commons Attribution License (CC BY). The use, distribution or reproduction in other forums is permitted, provided the original author(s) and the copyright owner(s) are credited and that the original publication in this journal is cited, in accordance with accepted academic practice. No use, distribution or reproduction is permitted which does not comply with these terms. 